\title{
Do Walking-Friendly Built Environments Influence Frailty and Long-Term Care Insurance Service Needs?
}

\author{
Seigo Mitsutake ${ }^{1,2, *}$, Tatsuro Ishizaki ${ }^{1}$, Yuri Yokoyama ${ }^{3}$, Mariko Nishi ${ }^{3}$, Mohammad Javad Koohsari ${ }^{4,5,6}{ }^{(\mathbb{C},}$ \\ Koichiro Oka ${ }^{4} \mathbb{D}^{\text {, }}$, Shohei Yano ${ }^{1,2,7} \mathbb{D}$, Takumi Abe ${ }^{8,9}$ and Akihiko Kitamura ${ }^{3}$
}

1 Human Care Research Team, Tokyo Metropolitan Institute of Gerontology, Tokyo 173-0015, Japan; tatsuro@tmig.or.jp (T.I.); shohei.yano@gmail.com (S.Y.)

2 Waseda Institute for Sport Sciences, Waseda University, Saitama 359-1192, Japan

3 Research Team for Social Participation and Community Health, Tokyo Metropolitan Institute of Gerontology, Tokyo 173-0015, Japan; yokoyama@tmig.or.jp (Y.Y.); nishi@tmig.or.jp (M.N.); kitamura@tmig.or.jp (A.K.)

4 Faculty of Sport Sciences, Waseda University, Saitama 359-1192, Japan; mkoohsari@unimelb.edu.au (M.J.K.); koka@waseda.jp (K.O.)

5 Melbourne School of Population and Global Health, The University of Melbourne, Melbourne, VIC 3053, Australia

6 Behavioural Epidemiology Laboratory, Baker Heart and Diabetes Institute, Melbourne, VIC 3004, Australia

7 The Salvation Army Booth Memorial Hospital, Tokyo 166-0012, Japan

8 Integrated Research Initiative for Living Well with Dementia, Tokyo Metropolitan Institute of Gerontology, Tokyo 173-0015, Japan; abe@tmig.or.jp

9 Centre for Urban Transitions, Swinburne University of Technology, Melbourne, VIC 3122, Australia

* Correspondence: mitsu@tmig.or.jp; Tel.: +81-3-3964-3241 (ext. 4229)

Citation: Mitsutake, S.; Ishizaki, T.; Yokoyama, Y.; Nishi, M.; Koohsari, M.J.; Oka, K.; Yano, S.; Abe, T.; Kitamura, A. Do Walking-Friendly Built Environments Influence Frailty and Long-Term Care Insurance Service Needs? Sustainability 2021, 13, 5632. https://doi.org/10.3390/ su13105632

Academic Editor: Gideon Baffoe

Received: 15 February 2021

Accepted: 13 May 2021

Published: 18 May 2021

Publisher's Note: MDPI stays neutral with regard to jurisdictional claims in published maps and institutional affiliations.

Copyright: (C) 2021 by the authors. Licensee MDPI, Basel, Switzerland. This article is an open access article distributed under the terms and conditions of the Creative Commons Attribution (CC BY) license (https:// creativecommons.org/licenses/by/ $4.0 /)$.

\begin{abstract}
Our study examined the associations between neighborhood walkability, frailty, and the incidence of long-term care insurance (LTCI) service needs using a prospective cohort survey in a suburban town in Japan. The final sample for analyses comprised 2867 community-dwelling older adults (mean age: 73.0 years). Neighborhood walkability was measured using the Walk Score ${ }^{\circledR}$. A total of 387 participants (13.5\%) exhibited frailty. The odds of frailty, adjusted for the covariates (sex, age, educational status, marital status, residential status, employment status, subjective economic status) among participants who lived in somewhat walkable/very walkable areas, was 0.750 (95\% Confidence Interval, CI: 0.597-0.943) versus those who lived in car-dependent areas. During the 23-month follow-up, 102 participants needed LTCI services (19.0 per 1000 person-years), 41 of whom (21.0 per 1000 person-years) lived in car-dependent areas, and 61 of whom (17.9 per 1000 personyears) lived in somewhat walkable/very walkable areas. As compared with participants who lived in car-dependent areas, the incidence of LTCI service needs was not significantly lower than that of those who lived in somewhat walkable/very walkable areas. Walk Score ${ }^{\circledR}$ can provide the critical information for the strategies to improve walkability and prevent older adults' frailty in less walkable areas, contributing to achieving the United Nation's Sustainable Development Goals (SDGs).
\end{abstract}

Keywords: health services for the aged; built environment; dependency; urban design

\section{Introduction}

The number of people aged 65 or older is projected to triple from an estimated 524 million in 2010 to nearly 1.5 billion in the world in 2050 [1]. With the rapid growth of the aging population, the World Health Organization has indicated that health is one of the most important goals of successful sustainable development in any city [2]. Frailty is common among older adults and a strong predictor of long-term care and medical care utilization [3-7]. For example, a recent study reported that the national prevalence of frailty was approximately $9 \%$ in community-dwelling older adults in Japan [6]. Therefore, it is essential to improve strategies for preventing frailty among older adults. Physical 
activity level appears to be inversely related to the risk of developing many chronic diseases, or physical and cognitive decline, which are the characteristics of frailty $[3,8,9]$. Improving neighborhood walkability is a population-based strategy that has been recommended to support physical activity [10-15]. For instance, recent prior systematic reviews found consistent evidence of higher accessibility and infrastructure for walking, cycling, and public transportation is associated with better physical activity [13,14]. In walkable neighborhoods, land use is mixed, with homes near commercial and institutional destinations, and streets are highly connected, providing direct routes from place to place [11]. Neighborhood walkability can influence health status by promoting healthy behaviors of individuals [16]. Most prior studies focused on the associations between the neighborhood environment and frailty, or functional status, in older adults in Western cities [17-23]; few such studies have been conducted in Japan [24-27]. Koohsari et al. highlighted the need for more evidence-based information regarding active-friendly neighborhood design from super-aged societies, such as Japan, to inform the broader international context [28]. Therefore, examining the role of neighborhood walkability in promoting older adults health, in super-aged societies, could contribute to implementing sustainable policies that promote health.

Assessing and measuring the built environment is the first step in developing walkable neighborhoods. Although geographic information systems (GIS) have been frequently used to assess neighborhood walkability objectively [29,30], this method is not easily used because it requires detailed geographic data, management of these data (cleaning data, merging with other data), and calculating necessary variables in a GIS software [31]. For example, a conventional walkability index requires land-use data for individual land parcels and retail floor area data for commercial parcels that are not readily available [32]. Data management and analysis using GIS software require trained personnel and special computational equipment. Therefore, policymakers and public healthcare staff may be unable to understand walkability using GIS easily. Walk Score ${ }^{\circledR}$ is a publicly available website, developed initially for real estate purposes, that calculates the number of nearby walkable destinations or amenities, which has emerged as a potential utility tool in public health [33]. Policymakers and public healthcare staff can easily assess the walkability of a resident through Walk Score ${ }^{\circledR}$, which is able to calculate walkability by inputting only an address. The Walk Score ${ }^{\circledR}$ algorithm calculates a walkability score based on the distance to destinations, such as grocery stores, coffee shops, restaurants, bookstores, banks, schools, parks, libraries, and fitness centers within $1.6 \mathrm{~km}$ from that location [24,34-36]. These raw scores are then normalized from 0 to 100 with adjustment by two street-network measures (intersection density and block length) around each location [24,35]. Higher scores represent areas with more walkable neighborhoods. Walk Score ${ }^{\circledR}$ appears to be a valid measure of certain aspects of neighborhood walkability in the US [36,37], Canada, and Japan [24,25]. Further, several studies have found positive associations between Walk Score ${ }^{\circledR}$ and walking for transport [38-40], as well as negative associations between Walk Score ${ }^{\circledR}$ and both body mass index [41,42] and hospitalization caused by heart attack [43]. However, to the best of our knowledge, no study has investigated the association between Walk Score ${ }^{\circledR}$ and frailty or the incidence of long-term care insurance (LTCI) service needs.

Examining the association between walkability, assessed by Walk Score ${ }^{\circledR}$, and frailty helps policymakers and public healthcare staff promote public health. With reference to prior studies that examined the association between walkability and frailty or functional status $[17-23,26,27,44]$, we hypothesized that higher Walk Score ${ }^{\circledR}$ would be associated with a lower risk of the prevalence of frailty or the incidence of LTCI service needs. Our study examined the associations between Walk Score ${ }^{\circledR}$ and both frailty and the incidence of LTCI service needs using a prospective cohort study among community-dwelling older adults, in a suburban town, in Japan. 


\section{Materials and Methods}

\subsection{Study Setting and Data Source}

A prospective cohort study was conducted in Hatoyama town, a suburban town in Saitama prefecture, located to the north of Tokyo, Japan. Hatoyama town has a population of 14,338 residents (population density 557.2 persons $/ \mathrm{km}^{2}$ in 2015), and approximately 39 percent of the population was aged over 65 years in 2015. The primary public transportation is three local bus routes to a train station in a neighboring city; there is no train station in Hatoyama town. In this study, the study population was 5735 older adults aged 65 years or older who were all residents in Hatoyama town on 1 December 2017. In January 2018, we conducted a questionnaire survey for a health condition, including frailty, among 5150 residents, aged 65 years or older, who had not received care needs certification of LTCI by 1 December 2017. We sent residents, aged 65 years or older, an envelope with a return address and paid postage together with a questionnaire. We also sent a letter of appreciation, and a reminder, to these residents on 26 January 2018. Moreover, we tracked the incidence of LTCI service needs among older adults after the questionnaire survey, using data on LTCI, needs certification linked to specific individuals who participated in our questionnaire survey.

\subsection{Independent Variable: Neighborhood Walkability}

Neighborhood walkability was measured using Walk Score ${ }^{\circledR}$ (score range: 0-100). Each residential address of the participants was entered into the Walk Score ${ }^{\circledR}$ website (www. walkscore.com), by two research staff members, independently, in 2019. Any discrepancy between the two research staff scores was checked and rectified by the first author. Prior studies used Walk Score ${ }^{\circledR}$ as both a continuous value and classified into four categories: (1) "car-dependent" (Walk Score ${ }^{\circledR}:$ 0-49), (2) "somewhat walkable" (Walk Score ${ }^{\circledR}$ : 50-69), (3) "very walkable" (Walk Score ${ }^{\circledR}:$ 70-89), and (4) "walker's paradise" (Walk Score ${ }^{\circledR}$ : 90-100) $[24,35-43,45]$. In this study, we examined the Walk Score ${ }^{\circledR}$ as both a continuous value and categorized.

\subsection{Outcome Variables: Frailty and the Incidence of LTCI Service Needs}

Frailty was the main outcome variable. We used the Kaigo-Yobo Checklist (KYCL) to assess frailty [46,47]. The KYCL comprises 15 questions (yes/no) within three subcategories: falling, nutritional status, and social activities [47]. The KYCL was validated against the modified Fried's criteria [46]. KYCL scores (cut-off point $=3 / 4$ ) discriminated frailty from non-frailty with sensitivity of $70.0 \%$ and specificity of $89.3 \%$ [46]. We used the cut-off for the frailty of $3 / 4$, based on prior studies $[7,46]$. The incidence of LTCI service needs was the secondary outcome variable. This incidence was defined as a new certification for LTCI service needs, as obtained from LTCI needs, certification data for Hatoyama town. The Japanese LTCI is a type of mandatory public social insurance that pays for LTCI services and is different from the medical insurance system [48,49]. All residents aged 40 and older pay LTCI premium, and those aged 65 and older (and those aged 40-64 with an aging-related disease such as terminal cancer) can be certified for LTCI service needs [48]. Entrusted investigators separately assess LTCI certification needs from responsible municipal governments and physicians, caring for seniors, who apply for certification by the LTCI system. Based on their reports regarding dependency in daily living activities and comorbidities, an examining, committee composed of municipal staff, medical doctors, and community health nurses with extensive experience in geriatrics, decides the need for certification and its grade by independent of the neighborhood environment [49]. We tracked new certifications for LTCI service needs for 23 months (from February 2018 to December 2019).

\subsection{Covariates}

To account for variations in participant characteristics, we selected other variables available that have previously been used as the covariates, namely sex, age, educational 
status, marital status, residential status, employment status, and subjective economic status $[41,43,45]$. Educational status was determined based on the highest level of education attained by each participant ("high school or lower," "two-year college or vocational college," or "university or higher"). For marital status, the participants were asked whether they were married or not and for residential status, the participants were asked if they lived "alone" or "with others." Participants were categorized as employed or not, with part-time workers considered "employed." Subjective economic status was assessed using a five-point scale and subsequently dichotomized as not poor ("very good," "good," and "normal") or poor ("very poor" and "poor").

\subsection{Statistical Analyses}

We analyzed the questionnaire survey on a baseline using chi-square tests to compare frailty percentages according to the various patient characteristics. We then examined the association between Walk Score ${ }^{\circledR}$ and frailty, using separate logistic regression models that treated Walk Score ${ }^{\circledR}$ as continuous or categorized, consistent with prior studies $[24,35-43,45]$. Each model adjusted for the covariates above.

Next, the cumulative probability of no LTCI service needs among participants who lived in areas of different Walk Score ${ }^{\circledR}$ categories was generated using the Kaplan-Meier method with a log-rank test for comparisons. A Cox proportional hazards model was constructed for the multivariate analysis, adjusted for the aforementioned covariates, with Walk Score ${ }^{\circledR}$ treated as continuous values and categorized in separate models. Participants who died $(n=51)$ or who moved out of Hatoyama town $(n=18)$ during the follow-up period were censored. Adjusted odds ratios and adjusted hazard ratio and their $95 \%$ confidence intervals (CIs) were calculated, and $p$-values (two-tailed) below 0.05 were considered statistically significant. All analyses were conducted using SPSS version 25.0 (IBM Corp., Armonk, NY, USA).

\section{Results}

\subsection{Participant}

Figure 1 shows a flow chart of the study participant selection. A total of 5150 questionnaires were sent in January 2018, and 3906 responses were obtained (response rate: $75.8 \%$ ); of these, 3232 participants provided usable data. We excluded seven participants who had received LTCI care needs certification between 2 December 2017, and January 2018. Furthermore, we excluded 357 participants who had missing responses for the KYCL or covariates. The final sample for analysis comprised 2867 participants. 


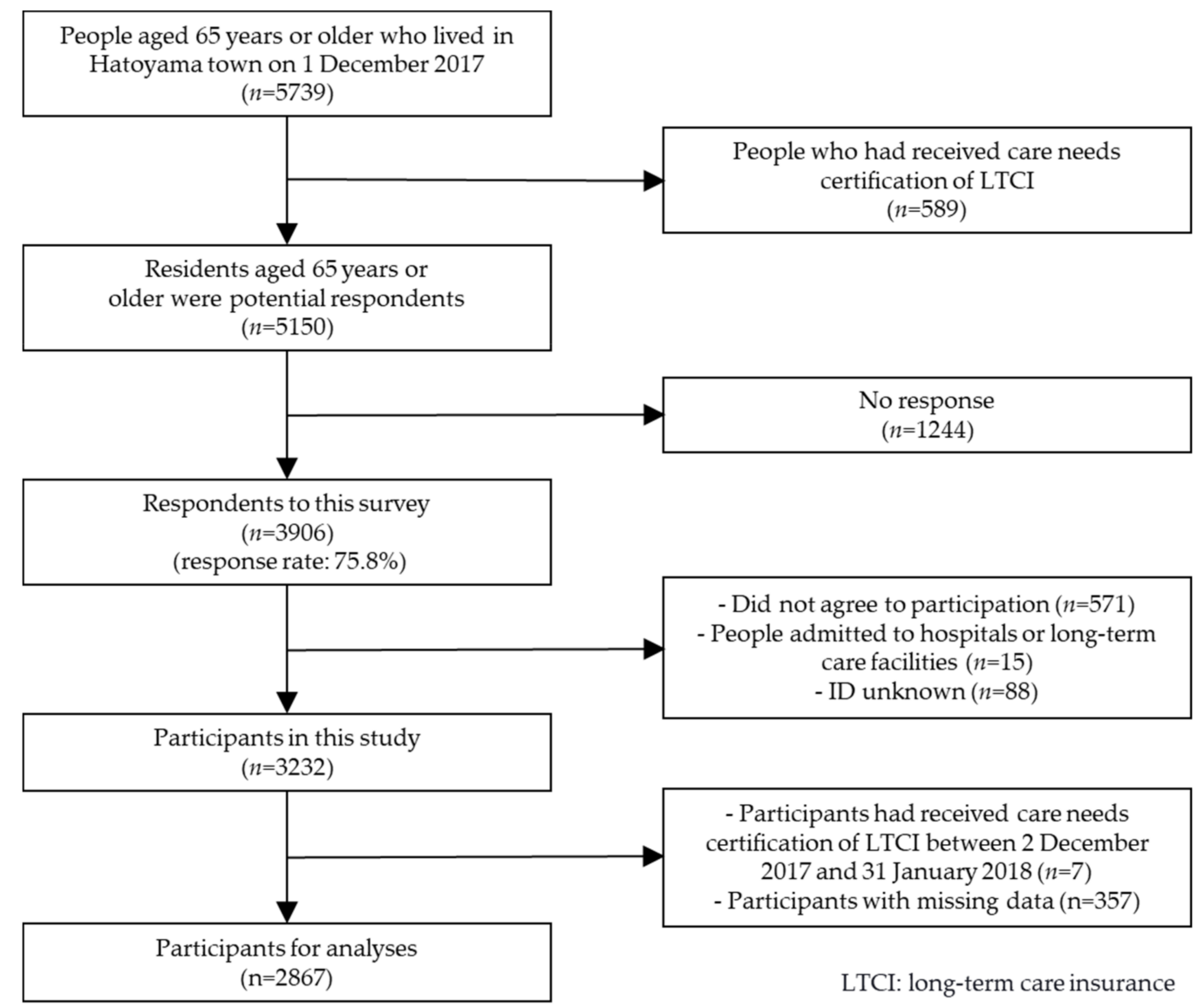

Figure 1. Flow chart of study participant selection process.

\subsection{Association between Neighborhood Walkability and Frailty}

The characteristics of the patients are summarized in Table 1 . The overall mean age was 73.0 years (standard deviation: 5.9 years). The overall mean Walk Score ${ }^{\circledR}$ was 47.8 (standard deviation: 16.0); 1043 participants (36.4\%) lived in car-dependent areas, 1824 participants $(63.6 \%)$ lived in somewhat walkable or very walkable areas, 1823 participants lived in somewhat walkable areas, one participant lived in a very walkable area, and no participants lived in a walker's paradise. We categorized Walk Score ${ }^{\circledR}$ as "car-dependent" or "somewhat walkable/very walkable," and indicated the map of categories of Walk Score ${ }^{\circledR}$ in Hatoyama town (Supplementary Figure S1). Participants living in car-dependent areas are less likely to graduate two-year college or vocational college, university and more likely to employ than those who lived in walkable/very walkable (Supplementary Table S1).

Approximately 387 participants $(13.5 \%)$ had frailty. Table 1 illustrates that the percentage of participants with frailty, who lived in somewhat walkable/very walkable areas $(12.4 \%)$, was lower than the respective percentage among participants who lived in cardependent areas $(15.4 \%)$. 
Table 1. Characteristics and percentage of frailty among participants $(n=2867)$.

\begin{tabular}{|c|c|c|c|c|}
\hline \multicolumn{2}{|r|}{ Characteristics } & \multirow{2}{*}{\begin{tabular}{c|}
$N$ \\
1043
\end{tabular}} & \multirow{2}{*}{$\begin{array}{c}\text { Frailty (\%) } \\
15.4\end{array}$} & \multirow{2}{*}{$\frac{p \text {-Value }^{\text {a }}}{0.022}$} \\
\hline Walk Score ${ }^{\circledR}$ category & Car-dependent & & & \\
\hline & Somewhat walkable/very walkable & 1824 & 12.4 & \\
\hline \multirow{2}{*}{ Sex } & Men & 1451 & 14.3 & 0.223 \\
\hline & Women & 1416 & 12.7 & \\
\hline \multirow[t]{3}{*}{ Age groups } & 65-74 year & 1849 & 10.3 & $<0.001$ \\
\hline & 75-79 year & 616 & 14.1 & \\
\hline & $\geq 80$ year & 402 & 27.4 & \\
\hline \multirow[t]{3}{*}{ Educational status } & High school or lower & 1748 & 15.0 & 0.014 \\
\hline & Two-year college or vocational college & 407 & 10.8 & \\
\hline & University or higher & 712 & 11.4 & \\
\hline \multirow[t]{2}{*}{ Marital status } & Unmarried & 553 & 18.3 & $<0.001$ \\
\hline & Married & 2314 & 12.4 & \\
\hline \multirow[t]{2}{*}{ Residential status } & Living with others & 2568 & 13.4 & 0.515 \\
\hline & Living alone & 299 & 14.7 & \\
\hline \multirow[t]{2}{*}{ Employment status } & Unemployed & 2045 & 16.1 & $<0.001$ \\
\hline & Employed & 822 & 7.1 & \\
\hline \multirow{2}{*}{$\begin{array}{l}\text { Subjective economic } \\
\text { status }\end{array}$} & Not poor & 2159 & 11.6 & $<0.001$ \\
\hline & Poor & 708 & 19.2 & \\
\hline
\end{tabular}

Abbreviations: Walk Score ${ }^{\circledR}$ : Car-dependent $=0-49$, Somewhat walkable $/$ very walkable $=50-89,{ }^{\text {a }}$ chi-square test.

Table 2 shows the association between neighborhood walkability and frailty in models that did and did not adjust for covariates. The adjusted odds of frailty among participants who lived in somewhat walkable/very walkable areas was 0.750 times (95\% CI: 0.597-0.943) that of participants who lived in car-dependent areas. Moreover, after adjusting for all covariates, there was a negative association between Walk Score ${ }^{\circledR}$ treated as a continuous variable and frailty (adjusted odds ratio, aOR: 0.989, 95\% CI: 0.982-0.995).

Table 2. Association between walkability and frailty $(n=2867)$.

\begin{tabular}{|c|c|c|c|c|}
\hline Characteristics & OR $(95 \% C I)$ & $p$-Value ${ }^{\mathrm{a}}$ & aOR (95\%CI) & $p$-Value ${ }^{\mathrm{b}}$ \\
\hline \multicolumn{5}{|l|}{ Walk Score ${ }^{\circledR}$ category } \\
\hline Car-dependent & Reference & & Reference & \\
\hline Somewhat walkable/very walkable & $0.775(0.623-0.964)$ & 0.022 & $0.750(0.597-0.943)$ & 0.014 \\
\hline Walk Score ${ }^{\circledR}$ (continuous values), per 1 unit increase & $0.989(0.983-0.995)$ & $<0.001$ & $0.989(0.982-0.995)$ & 0.001 \\
\hline
\end{tabular}

Abbreviations: OR, odds ratio; aOR, adjusted odds ratio; CI, confidence interval. ${ }^{\text {a }}$ Logistic regression analysis, ${ }^{\mathrm{b}}$ Multivariable logistic regression analysis adjusted for all covariates (sex, age, educational status, marital status, residential status, employment status, subjective economic status).

\subsection{Association between Neighborhood Walkability and LTCI Service Needs}

Figure 2 shows the Kaplan-Meier curves for overall LTCI service needs for participants who lived in car-dependent areas and participants who lived in somewhat walkable/very walkable areas. During the 23-month follow-up period, 102 participants needed LTCI services (19.0 per 1000 person-years), 41 participants of whom (21.0 per 1000 personyears) lived in car-dependent areas, and 61 of whom (17.9 per 1000 person-years) lived in somewhat walkable/very walkable areas. 


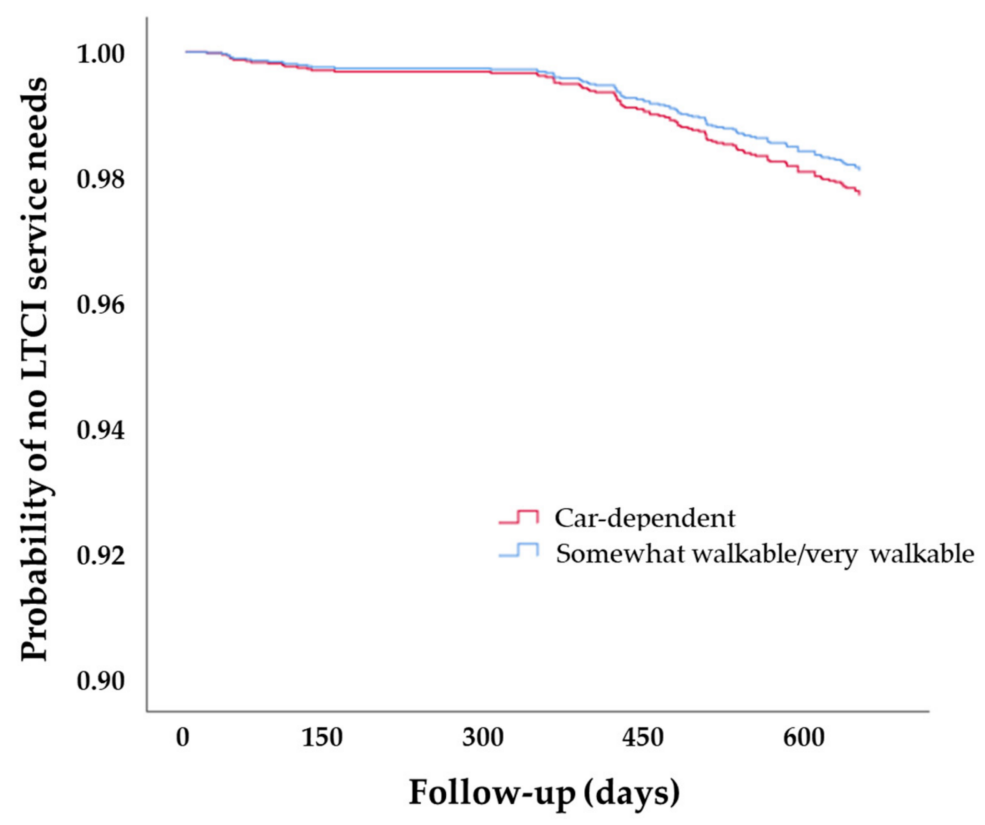

Numbers at risk

Car-dependent

$1043 \quad 1036$

1027

1010

989

Somewhat walkable/Very walkable

1824

1807

1794

1768

1739

Figure 2. Long-term care insurance service needs comparing Walk Score ${ }^{\circledR}$ categories during follow-up.

Table 3 shows Cox proportional hazards analyses adjusted, and not adjusted, for all covariates. After adjusting, the incidence of LTCI service needs was lower among participants who lived in somewhat walkable/very walkable areas than participants who lived in car-dependent areas. However, the hazard ratio was not significantly different from unity (adjusted hazard ratio, aHR: 0.827, 95\% CI: 0.553-1.239). Moreover, no significant reduction in risk was observed for the incidence of LTCI service needs by Walk Score ${ }^{\circledR}$ increase, with Walk Score ${ }^{\circledR}$ treated as a continuous variable (aHR: 0.993, 95\% CI: 0.982-1.004).

Table 3. Cox proportional hazards analysis comparing long-term care insurance service needs by Walk Score ${ }^{\circledR}$.

\begin{tabular}{|c|c|c|c|c|}
\hline & HR $(95 \%$ CI) & $p$-Value ${ }^{a}$ & aHR $(95 \%$ CI) & $p$-Value ${ }^{b}$ \\
\hline \multicolumn{5}{|l|}{ Walk Score ${ }^{\circledR}$ category } \\
\hline Car-dependent & Reference & & Reference & \\
\hline Somewhat walkable/Very walkable & $0.849(0.572-1.262)$ & 0.419 & $0.827(0.553-1.239)$ & 0.357 \\
\hline Walk Score ${ }^{\circledR}$ (continuous values), per 1 unit increase & $0.991(0.981-1.002)$ & 0.123 & $0.993(0.982-1.004)$ & 0.225 \\
\hline
\end{tabular}

Abbreviations: HR, hazard ratio; aHR, adjusted hazard ratio; CI, confidence interval. ${ }^{a}$ Cox proportional hazards analysis. ${ }^{\mathrm{b}}$ Cox proportional hazards analysis adjusted for all covariates (sex, age, educational status, marital status, residential status, employment status, subjective economic status).

\section{Discussion}

The present study examined the associations between neighborhood walkability and both frailty and the incidence of LTCI service needs among older adults, in a suburban town, in Japan. We found significant negative associations between neighborhood walkability assessed by Walk Score ${ }^{\circledR}$ and frailty. However, neighborhood walkability was not associated with the incidence of LTCI service needs for 23 months following our initial cross-sectional survey. As no prior study has examined the association between walkability and the incidence of LTCI service needs, further research may be needed that extends the follow-up period during which LTCI service needs are assessed.

The risk of frailty among participants who lived in somewhat walkable/very walkable areas was 0.75 that of participants who lived in car-dependent areas. Health and wellbeing are essential to achieving the United Nation's Sustainable Development Goals (SDGs), 
and improving strategies for preventing frailty plays a vital role in promoting health and wellbeing for older adults [2]. Therefore, Walk Score ${ }^{\circledR}$ provides valuable urban design insights on improving walkability and preventing older adults' frailty in less walkable areas. Moreover, this finding is consistent with several previous studies that revealed associations between walkability and frailty, or physical function, among older adults [17-23,26,44]. There are several reasons why older adults, who live in more walkable areas, have a lower risk of frailty than older adults who live in less walkable areas. Prior studies reported that more walkable areas positively influenced greater physical activity among older adults [10-12]. Moreover, prior studies also showed that older adults who live in walkable areas have better opportunities to interact with their neighbors and have better social capital [50-53], which may lower the risk of frailty by preventing chronic disease or functional decline [54-56]. However, as the present study did not examine the causal pathway from neighborhood walkability and frailty, a future study would be required to identify the mechanism for the association between neighborhood walkability and frailty.

Although the incidence of LTCI service needs was lower among participants who lived in somewhat walkable/very walkable areas than participants who lived in cardependent areas, the difference was not significant. The current data revealed that only 102 participants needed LTCI services during the 23-month follow-up period. The followup period for the incidence of LTCI service needs in the current study could have been too short for examining the difference in the incidence of LTCI service needs between older adults who lived in less walkable versus more walkable areas. To our knowledge, no other study has examined the influence of walkability on the incidence of LTCI service needs. Therefore, further research examining the association between walkability and incidence of LTCI service needs is needed with an extended follow-up period or bigger sample size to increase the incidence of LTCI service needs.

There were several limitations to this study. First, the participants of this study lived in one suburban town. A prior study showed that the rate of frailty among older adults who lived in suburban areas was lower than that of those living in metropolitan or rural areas [7]. Therefore, this study's rate of frailty could be lower than in urban areas or rural areas. Moreover, there were no participants who lived in a "walker's paradise" in this study. The risk of frailty among older adults who live in an area classified as a walker's paradise would be lower than the risk of frailty among older adults who live in less walkable areas because this study found a negative linear association between Walk Score ${ }^{\circledR}$ and frailty. This study could have underestimated the association between walkability and the risk of frailty instead of a study comparing the association between walkability and risk of frailty in areas ranging from car-dependent to walker's paradise. Second, using the KYCL to determine the frailty represents a limitation of this study, although the KYCL has good concurrent and predictive validity with Fried's frailty criteria [46]. As the prevalence of frailty, in this study, was higher than the prevalence of frailty in a recent national study that used Fried's frailty criteria [6], the prevalence of frailty in the current study could be overestimated as compared with the prevalence of frailty among the general population of older adults in Japan. Third, our assessments of walkability were limited to the baseline and did not consider any possible changes due to moves within Hatoyama town over the study period. As Walk Score ${ }^{\circledR}$ did not identify the association of detailed geographic characteristics, such as intersection density, or land use with frailty, future studies would need to examine the association of detailed geographic characteristics with frailty using GIS data. Finally, we did not adjust for potential confounding factors such as psychosocial factors (e.g., self-efficacy) [57]. This study's strength is that it is the first to examine the association between neighborhood walkability, frailty, and incidence of LTCI service needs using a prospective study in Japan. The evidence provided by this study may contribute to policy implementation to promote health in aging societies. 


\section{Conclusions}

The present study found a negative association between neighborhood walkability, assessed by Walk Score ${ }^{\circledR}$, and frailty. Walk Score ${ }^{\circledR}$ can provide the information for consideration of the strategies to improve walkability and prevent older adults' frailty in less walkable areas. Improving strategies for preventing frailty plays a vital role in promoting health and wellbeing for older adults, contributing to achieving the SDGs.

Supplementary Materials: The following are available online at https:/ / www.mdpi.com/article/10 $.3390 /$ su13105632/s1, Figure S1. Walk Score ${ }^{\circledR}$ categories in the study area; Table S1. Characteristics between participants who lived in car-dependent areas and somewhat walkable/very walkable areas $(n=2867)$.

Author Contributions: Conceptualization, S.M., M.J.K. and K.O.; Data curation, S.M., Y.Y., M.N., T.A. and A.K.; Formal analysis, S.M. and S.Y.; Funding acquisition, S.M. and A.K.; Investigation, Y.Y., M.N. and A.K.; Methodology, S.M., T.I., M.J.K., K.O. and A.K.; Project administration, A.K.; Supervision, T.I. and A.K.; Validation, S.M. and S.Y.; Visualization, S.M.; Writing-original draft, S.M.; Writing—review \& editing, S.M., T.I., Y.Y., M.N., M.J.K., K.O., S.Y., T.A. and A.K. All authors have read and agreed to the published version of the manuscript.

Funding: This research was funded by The Japan Foundation for Aging and Health, Rokenjigyo from the Ministry of Health, Labour and Welfare, Japan, and Research Grant 2019 from Daiwa Securities Health Foundation.

Institutional Review Board Statement: The study was conducted according to the guidelines of the Declaration of Helsinki and approved by the Ethical Committee of Tokyo Metropolitan Institute of Gerontology (Approval No: 32, date of approval: 5 August 2010, Approval No: 28, date of approval: 27 January 2016, Approval No: 38, date of approval: 27 December 2017).

Informed Consent Statement: All participants gave written consent to participate in this study.

Data Availability Statement: The data set supporting these findings is not publicly available due to access restrictions imposed by the Ethical Committee of Tokyo Metropolitan Institute of Gerontology. Public data sharing is restricted in order to protect privacy and confidentiality. Data requests from any interested researcher may be sent to the corresponding author (SM): mitsu@tmig.or.jp.

Acknowledgments: We are grateful to the city staff of Hatoyama Town Office, as well as to all study participants.

Conflicts of Interest: The authors declare no conflict of interest.

\section{References}

1. Zeglinski-Spinney, A.; Wai, D.C.; Phan, P.; Tsai, E.C.; Stratton, A.; Kingwell, S.P.; Roffey, D.M.; Wai, E.K. Increased Prevalence of Chronic Disease in Back Pain Patients Living in Car-dependent Neighbourhoods in Canada: A Cross-sectional Analysis. J. Prev. Med. Public Health 2018, 51, 227-233. [CrossRef] [PubMed]

2. World Health Organization. Shanghai declaration on promoting health in the 2030 Agenda for Sustainable Development. Health Promot. Int. 2017, 32, 7-8. [CrossRef] [PubMed]

3. Ferrucci, L.; Fabbri, E.; Walston, J.D. Frailty. In Hazzard's Geriatric Medicine and Gerontology, 7th ed.; Ouslander, J.G., Studenski, S., High, K.P., Asthana, S., Supiano, M.A., Ritchie, C.S., Eds.; McGraw-Hill Education: New York, NY, USA, 2017 ; pp. 691-708.

4. Buta, B.J.; Walston, J.D.; Godino, J.G.; Park, M.; Kalyani, R.R.; Xue, Q.L.; Bandeen-Roche, K.; Varadhan, R. Frailty assessment instruments: Systematic characterization of the uses and contexts of highly-cited instruments. Ageing Res. Rev. 2016, $26,53-61$. [CrossRef] [PubMed]

5. $\quad$ Bandeen-Roche, K.; Seplaki, C.L.; Huang, J.; Buta, B.; Kalyani, R.R.; Varadhan, R.; Xue, Q.L.; Walston, J.D.; Kasper, J.D. Frailty in Older Adults: A Nationally Representative Profile in the United States. J. Gerontol. A Biol. Sci. Med. Sci. 2015, 70, 1427-1434. [CrossRef]

6. Murayama, H.; Kobayashi, E.; Okamoto, S.; Fukaya, T.; Ishizaki, T.; Liang, J.; Shinkai, S. National prevalence of frailty in the older Japanese population: Findings from a nationally representative survey. Arch. Gerontol. Geriatr. 2020, 91, 104220. [CrossRef]

7. Abe, T.; Kitamura, A.; Seino, S.; Yokoyama, Y.; Amano, H.; Taniguchi, Y.; Nishi, M.; Narita, M.; Ikeuchi, T.; Tomine, Y.; et al. Differences in the Prevalence of and Factors Associated with Frailty in Five Japanese Residential Areas. Int. J. Environ. Res. Public Health 2019, 16, 3974. [CrossRef]

8. Thompson, P.D.; Eijsvogels, T.M. New physical activity guidelines: A call to activity for clinicians and patients. JAMA 2018, 320, 1983-1984. [CrossRef] 
9. Hildreth, K.L.; Melanson, E.L.; Moreau, K.L. Exercise: Pysiologin and functional effects. In Hazzard's Geriatric Medicine and Gerontology, 7th ed.; Ouslander, J.G., Studenski, S., High, K.P., Asthana, S., Supiano, M.A., Ritchie, C.S., Eds.; McGraw-Hill Education: New York, NY, USA, 2017; pp. 1755-1774.

10. Cervero, R.; Duncan, M. Walking, bicycling, and urban landscapes: Evidence from the San Francisco Bay Area. Am. J. Public Health 2003, 93, 1478-1483. [CrossRef]

11. Sallis, J.F.; Floyd, M.F.; Rodríguez, D.A.; Saelens, B.E. Role of built environments in physical activity, obesity, and cardiovascular disease. Circulation 2012, 125, 729-737. [CrossRef]

12. Saelens, B.E.; Sallis, J.F.; Frank, L.D. Environmental correlates of walking and cycling: Findings from the transportation, urban design, and planning literatures. Ann. Behav. Med. 2003, 25, 80-91. [CrossRef]

13. Kärmeniemi, M.; Lankila, T.; Ikäheimo, T.; Koivumaa-Honkanen, H.; Korpelainen, R. The Built Environment as a Determinant of Physical Activity: A Systematic Review of Longitudinal Studies and Natural Experiments. Ann. Behav. Med. 2018, 52, 239-251. [CrossRef]

14. Hajna, S.; Ross, N.A.; Brazeau, A.S.; Bélisle, P.; Joseph, L.; Dasgupta, K. Associations between neighbourhood walkability and daily steps in adults: A systematic review and meta-analysis. BMC Public Health 2015, 15, 768. [CrossRef]

15. Tao, Y.; Zhang, W.; Gou, Z.; Jiang, B.; Qi, Y. Planning walkable neighborhoods for "aging in place": Lessons from five agingfriendly districts in Singapore. Sustainability 2021, 13, 1742. [CrossRef]

16. Sallis, J.F.; Owen, N.; Fisher, E. Ecological models of health behavior. In Health Behavior: Theory, Research, and Practice; Jossey-Bass Inc.: San Francisco, CA, USA, 2015; Volume 5.

17. Balfour, J.L.; Kaplan, G.A. Neighborhood Environment and Loss of Physical Function in Older Adults: Evidence from the Alameda County Study. Am. J. Epidemiol. 2002, 155, 507-515. [CrossRef]

18. Fogal, A.S.; Pessoa, M.C.; Fernandes Filho, E.I.; Ribeiro, A.Q. Built urban environment and functional incapacity: Enabling healthy aging. J. Transp. Health 2019, 14, 100574. [CrossRef]

19. de Keijzer, C.; Tonne, C.; Sabia, S.; Basagana, X.; Valentin, A.; Singh-Manoux, A.; Anto, J.M.; Alonso, J.; Nieuwenhuijsen, M.J.; Sunyer, J.; et al. Green and blue spaces and physical functioning in older adults: Longitudinal analyses of the Whitehall II study. Environ. Int. 2019, 122, 346-356. [CrossRef]

20. Arakawa Martins, B.; Taylor, D.; Barrie, H.; Lange, J.; Sok Fun Kho, K.; Visvanathan, R. Objective and subjective measures of the neighbourhood environment: Associations with frailty levels. Arch. Gerontol. Geriatr. 2020, 92, 104257. [CrossRef]

21. Michael, Y.L.; Gold, R.; Perrin, N.A.; Hillier, T.A. Built environment and lower extremity physical performance: Prospective findings from the study of osteoporotic fractures in women. J. Aging Health 2011, 23, 1246-1262. [CrossRef]

22. Clarke, P.J. The role of the built environment and assistive devices for outdoor mobility in later life. J. Gerontol. B Psychol. Sci. Soc. Sci. 2014, 69, S8-S15. [CrossRef]

23. Brenner, A.B.; Clarke, P.J. Understanding Socioenvironmental Contributors to Racial and Ethnic Disparities in Disability Among Older Americans. Res. Aging 2018, 40, 103-130. [CrossRef]

24. Koohsari, M.J.; Sugiyama, T.; Hanibuchi, T.; Shibata, A.; Ishii, K.; Liao, Y.; Oka, K. Validity of Walk Score(R) as a measure of neighborhood walkability in Japan. Prev. Med. Rep. 2018, 9, 114-117. [CrossRef] [PubMed]

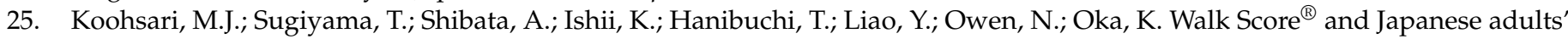
physically-active and sedentary behaviors. Cities 2018, 74, 151-155. [CrossRef]

26. Martins, B.A.; Visvanathan, R.; Barrie, H.R.; Huang, C.H.; Matsushita, E.; Okada, K.; Satake, S.; Edwards, S.; Uno, C.; Kuzuya, M. Built Environment and Frailty: Neighborhood Perceptions and Associations with Frailty, Experience From the Nagoya Longitudinal Study. J. Appl. Gerontol. 2020, 733464820912663. [CrossRef] [PubMed]

27. Soma, Y.; Tsunoda, K.; Kitano, N.; Jindo, T.; Tsuji, T.; Saghazadeh, M.; Okura, T. Relationship between built environment attributes and physical function in Japanese community-dwelling older adults. Geriatr. Gerontol. Int. 2017, 17, 382-390. [CrossRef]

28. Koohsari, M.J.; Nakaya, T.; Oka, K. Activity-Friendly Built Environments in a Super-Aged Society, Japan: Current Challenges and toward a Research Agenda. Int. J. Environ. Res. Public Health 2018, 15, 2054. [CrossRef]

29. Telega, A.; Telega, I.; Bieda, A. Measuring walkability with GIS-Methods overview and new approach proposal. Sustainability 2021, 13, 1883. [CrossRef]

30. Sallis, J.F. Measuring physical activity environments: A brief history. Am. J. Prev. Med. 2009, 36, S86-S92. [CrossRef]

31. Brownson, R.C.; Hoehner, C.M.; Day, K.; Forsyth, A.; Sallis, J.F. Measuring the built environment for physical activity: State of the science. Am. J. Prev. Med. 2009, 36, S99-S123.e112. [CrossRef]

32. Frank, L.D.; Sallis, J.F.; Saelens, B.E.; Leary, L.; Cain, K.; Conway, T.L.; Hess, P.M. The development of a walkability index: Application to the Neighborhood Quality of Life Study. Br. J. Sports Med. 2010, 44, 924-933. [CrossRef]

33. Duncan, D.T. What's your Walk Score $(\mathrm{R})$ ? Web-based neighborhood walkability assessment for health promotion and disease prevention. Am. J. Prev. Med. 2013, 45, 244-245. [CrossRef]

34. Walkscore ${ }^{\circledR}$. Walk Score Methodology. Available online: https://www.walkscore.com/ (accessed on 20 November 2020).

35. Nykiforuk, C.I.; McGetrick, J.A.; Crick, K.; Johnson, J.A. Check the score: Field validation of street smart walk score in Alberta, Canada. Prev. Med. Rep. 2016, 4, 532-539. [CrossRef]

36. Carr, L.J.; Dunsiger, S.I.; Marcus, B.H. Walk score as a global estimate of neighborhood walkability. Am. J. Prev. Med. 2010, 39, 460-463. [CrossRef] 
37. Carr, L.J.; Dunsiger, S.I.; Marcus, B.H. Validation of Walk Score for estimating access to walkable amenities. Br. J. Sports Med. 2011, 45, 1144-1148. [CrossRef]

38. Hirsch, J.A.; Moore, K.A.; Evenson, K.R.; Rodriguez, D.A.; Diez Roux, A.V. Walk Score(R) and Transit Score(R) and walking in the multi-ethnic study of atherosclerosis. Am. J. Prev. Med. 2013, 45, 158-166. [CrossRef]

39. Cole, R.; Dunn, P.; Hunter, I.; Owen, N.; Sugiyama, T. Walk Score and Australian adults' home-based walking for transport. Health Place 2015, 35, 60-65. [CrossRef]

40. Chudyk, A.M.; McKay, H.A.; Winters, M.; Sims-Gould, J.; Ashe, M.C. Neighborhood walkability, physical activity, and walking for transportation: A cross-sectional study of older adults living on low income. BMC Geriatr. 2017, 17, 82. [CrossRef]

41. Meline, J.; Chaix, B.; Pannier, B.; Ogedegbe, G.; Trasande, L.; Athens, J.; Duncan, D.T. Neighborhood walk score and selected Cardiometabolic factors in the French RECORD cohort study. BMC Public Health 2017, 17, 960. [CrossRef]

42. Hirsch, J.A.; Diez Roux, A.V.; Moore, K.A.; Evenson, K.R.; Rodriguez, D.A. Change in walking and body mass index following residential relocation: The multi-ethnic study of atherosclerosis. Am. J. Public Health 2014, 104, e49-e56. [CrossRef]

43. Mazumdar, S.; Learnihan, V.; Cochrane, T.; Phung, H.; O'Connor, B.; Davey, R. Is Walk Score associated with hospital admissions from chronic diseases? Evidence from a cross-sectional study in a high socioeconomic status Australian city-state. BMJ Open 2016, 6, e012548. [CrossRef]

44. Koohsari, M.J.; McCormack, G.R.; Nakaya, T.; Shibata, A.; Ishii, K.; Yasunaga, A.; Liao, Y.; Oka, K. Walking-friendly built environments and objectively measured physical function in older adults: Urban design and older adults' physical function. $J$. Sport Health Sci. 2020, 9, 651-656. [CrossRef]

45. Liao, Y.; Lin, C.Y.; Lai, T.F.; Chen, Y.J.; Kim, B.; Park, J.H. Walk Score((R)) and Its Associations with Older Adults' Health Behaviors and Outcomes. Int. J. Environ. Res. Public Health 2019, 16, 622. [CrossRef]

46. Shinkai, S.; Watanabe, N.; Yoshida, H.; Fujiwara, Y.; Nishi, M.; Fukaya, T.; Lee, S.; Kim, M.J.; Ogawa, K.; Murayama, H.; et al. Validity of the "Kaigo-Yobo Check-List" as a frailty index. Nihon Koshu Eisei Zasshi 2013, 60, 262-274.

47. Shinkai, S.; Yoshida, H.; Taniguchi, Y.; Murayama, H.; Nishi, M.; Amano, H.; Nofuji, Y.; Seino, S.; Fujiwara, Y. Public health approach to preventing frailty in the community and its effect on healthy aging in Japan. Geriatr. Gerontol. Int. 2016, 16, 87-97. [CrossRef]

48. Ministry of Health, Labour and Welfare. Long-Term Care Insurance System of Japan. Available online: https:/ /www.mhlw.go. jp/english/policy/care-welfare/care-welfare-elderly/dl/ltcisj_e.pdf (accessed on 5 April 2021).

49. Tsutsui, T.; Muramatsu, N. Care-needs certification in the long-term care insurance system of Japan. J. Am. Geriatr. Soc. 2005, 53, 522-527. [CrossRef]

50. Rogers, S.; Gardner, K.; Carlson, C. Social Capital and Walkability as Social Aspects of Sustainability. Sustainability 2013, 5, 3473-3483. [CrossRef]

51. Rogers, S.H.; Halstead, J.M.; Gardner, K.H.; Carlson, C.H. Examining Walkability and Social Capital as Indicators of Quality of Life at the Municipal and Neighborhood Scales. Appl. Res. Qual. Life 2011, 6, 201-213. [CrossRef]

52. Zhu, X.; Yu, C.Y.; Lee, C.; Lu, Z.; Mann, G. A retrospective study on changes in residents' physical activities, social interactions, and neighborhood cohesion after moving to a walkable community. Prev. Med. 2014, 69, S93-S97. [CrossRef]

53. Hwang, E.; Brossoie, N.; Jeong, J.W.; Song, K. The impacts of the neighborhood built environment on social capital for middle-aged and elderly Koreans. Sustainability 2021, 13, 756. [CrossRef]

54. Valtorta, N.K.; Kanaan, M.; Gilbody, S.; Ronzi, S.; Hanratty, B. Loneliness and social isolation as risk factors for coronary heart disease and stroke: Systematic review and meta-analysis of longitudinal observational studies. Heart 2016, 102, 1009-1016. [CrossRef]

55. Shankar, A.; McMunn, A.; Banks, J.; Steptoe, A. Loneliness, social isolation, and behavioral and biological health indicators in older adults. Health Psychol. 2011, 30, 377-385. [CrossRef] [PubMed]

56. Fujita, K.; Fujiwara, Y.; Chaves, P.H.; Motohashi, Y.; Shinkai, S. Frequency of going outdoors as a good predictors for incident disability of physical function as well as disability recovery in community-dwelling older adults in rural Japan. J. Epidemiol. 2006, 16, 261-270. [CrossRef] [PubMed]

57. Carlson, J.A.; Sallis, J.F.; Conway, T.L.; Saelens, B.E.; Frank, L.D.; Kerr, J.; Cain, K.L.; King, A.C. Interactions between psychosocial and built environment factors in explaining older adults' physical activity. Prev. Med. 2012, 54, 68-73. [CrossRef] [PubMed] 